\title{
The gene for Campylobacter trigger factor: evidence for multiple transcription start sites and protein products
}

\author{
Phillippa L. Griffiths, ${ }^{1}$ Robert W. A. Park ${ }^{2}$ and Ian F. Connerton ${ }^{3}$
}

Author for correspondence: Phillippa L. Griffiths. Tel: +44 171 5945254. Fax: +441715945255.

\author{
1 Department of \\ Biochemistry, Imperial \\ College of Science, \\ Technology and Medicine, \\ Exhibition Road, London \\ SW7 2AZ, UK \\ 2 Department of \\ Microbiology, University of \\ Reading, PO Box 228, \\ Reading RG6 2AJ, UK \\ 3 Department of Protein \\ Engineering, Institute of \\ Food Research, Reading \\ Laboratory, Earley Gate, \\ Whiteknights Road, \\ Reading RG6 2EF, UK
}

\begin{abstract}
A gene encoding a protein of apparent molecular mass $56 \mathrm{kDa}$ that shares $31 \%$ identity with the amino acid sequence of trigger factor from Escherichia coli (a protein thought to be involved in cell division), was cloned from

Campylobacter jejuni NCTC 11168. The clone was selected from a lambda ZAP II genomic DNA library following an immuno-screen using antiserum raised against glycine-extractable proteins from $\mathrm{C}$. jejuni. The gene has two potential initiation codons, giving rise to two possible nested protein products. Complex differential growth-phase-dependent transcripts give rise to these products.
\end{abstract}

Keywords: Campylobacter jejuni, trigger factor, tig, ClpP protease, GTP cyclohydrolase

\section{INTRODUCTION}

Campylobacters are an important cause of diarrhoeal disease throughout the world (Griffiths \& Park, 1990) but despite many years of research, little is known about the structure and function of the majority of membrane proteins and other important protein antigens of Campylobacter jejuni. Due to problems of clonal instability with Campylobacter DNA (Walker et al., 1986) progress has not been as rapid as with other pathogenic bacteria. However, some genes, including those encoding flagellin proteins and some with housekeeping functions, have now been cloned and sequenced (reviewed by Taylor, 1992).

When examining sera obtained from human patients after a recent infection with $C$. jejuni it is not uncommon to find no discernible antibody response to Campylobacter antigens above control levels. For example, one study, using human volunteers (Black et al., 1992), found only $8 / 18(44 \%)$ of individuals seroconverted in two immunoglobulin classes by ELISA (the criterion often used to discriminate a positive seroconversion from negative). The reason for the lack of seroconversion in some individuals is not known. In those individuals who do seroconvert, the sera obtained can react with Campylobacter whole cells and with outer-membrane preparations in Western blotting experiments, revealing several distinct proteins to be immunogenic during infection, many of

Abbreviation: $A E$, acid-glycine extracts.

The EMBLGenBank/DDBJ accession number for the sequence reported in this paper is $X 85954$. which are common to most strains (Blaser et al., 1984; Mills \& Bradbury, 1984; Nachamkin \& Hart, 1985). However, sera from non-infected controls may also react with Campylobacter proteins (Blaser et al., 1984; Mills \& Bradbury, 1984; Nachamkin \& Hart, 1985; Panigrahi et $a l ., 1992)$ and therefore the reactions using convalescent sera may not always be clear-cut. The common proteins consistently recognized by infected patient sera are also to be found in acid-glycine extracts (AE) of Campylobacter (Blaser \& Duncan, 1984) and such extracts are often used in ELISA assays as a standard antigen preparation (Svedhem et al., 1983; Blaser \& Duncan, 1984; Herbrink et al., 1988). The major components of $\mathrm{AE}$ are flagellin (approximately $62 \mathrm{kDa}$ ), acid-extractable membrane proteins and other proteins probably derived from the periplasm (Logan \& Trust, 1983). Of these components most attention has focused on flagellin and its genes, which are interesting for a number of reasons; the flagellum is thought to be important in invasion (Wassenaar et al., 1991), there are two full-length flagellin genes $f a A$ and $f l a B$, and expression of flagella is subject to antigenic variation, as a result of rearrangement of flagellin sequence information together with rDNA sequences (Guerry et al., 1990, 1992). The presence of duplicated flagellin genes is thought to confer a mechanism by which the organism can maintain motility even in the event of mutation in one copy of the gene (Alm et al., 1993). In addition, the maintenance of two fla genes probably confers structural and regulatory advantages on the organism (Guerry et al., 1991). Another component of $\mathrm{AE}$ that has been investigated is the $28 \mathrm{kDa}$ protein $\mathrm{PEB} 1$ (Pei \& Blaser, 1993) that was originally described as a cell 
binding factor, but which has a very high degree of similarity to the transport proteins of Escherichia coli, $g \ln Q$ and bisP.

We have initiated studies on non-flagellar genes encoding antigenic proteins in $\mathrm{AE}$ and their relationship to pathogenicity and protective immunity. Such antigenic proteins are interesting in their own right, but in addition they may be directly or indirectly involved in the disease process. However, it is entirely possible that the immunogenicity of such proteins is purely coincidental, occurring as a result of bacterial breakdown and antigen presentation exposing epitopes that would not normally be seen by the host immune system. It is therefore necessary to closely study this group of antigenic proteins, so as to assign possible functions and to confirm or exclude their role in disease.

\section{METHODS}

Bacterial strains and growth conditions. Campylobacter jejuni NCTC (National Collection of Type Cultures, Colindale, UK) strain 11168 was used to construct the lambda expression library and for the transcript mapping experiments. It was cultured on blood agar base (Oxoid, CM 271) with $5 \%$ (v/v) defibrinated horse blood (Tissue Culture Services) and incubated at $37^{\circ} \mathrm{C}$ under microaerobic conditions using the partial evacuation/ replacement technique (Bolton \& Coates, 1993). The replacement gas mix contained $10 \%$ (v/v) $\mathrm{H}_{2}, 10 \%$ (v/v) $\mathrm{CO}_{2}$ in $\mathrm{N}_{2}$ (BOC). Escbericbia coli strain PLKF' (obtained from Stratagene) was used as the host for the cloning and expression experiments; it was grown on Luria Bertani (LB) agar or broth (Maniatis $e t$ al., 1982) and incubated at $37^{\circ} \mathrm{C}$.

Production of antiserum. Acid-glycine extraction of $C$. jejuni was carried out using the method of McCoy et al. (1975) and protein material inoculated into adult Dutch Half Lop rabbits using Freund's adjuvants according to standard procedures. The antiserum produced was absorbed with PLKF $^{\prime}$ whole cells prior to screening the library, to remove non-specific antibodies. Convalescent serum was obtained from six patients diagnosed as suffering from Campylobacter enteritis.

Isolation of DNA and construction of C. jejuni gene library. A lambda ZAP II (Stratagene) library was constructed using sonicated 2-10 kb DNA fragments of Campylobacter chromosomal DNA. Sheared ends were made flush with T4 DNA polymerase. Internal EcoRI sites were methylated before the fragments were ligated to phosphorylated EcoRI linkers and cleaved with $E c o$ RI to generate 'sticky ends'. The fragments were then ligated to EcoRI pre-prepared lambda arms and packaged into phage heads. Recombinant phage $\left(\sim 2 \times 10^{4}\right)$ were plated out, induced with IPTG and screened with antibody using established procedures (Short $e t$ al., 1988). Positive clone $10 \mathrm{a}$ was picked and the recombinant insert excised from lambda as a pBluescript phagemid (10a1) to enable further analysis.

DNA sequence analysis. 10a1 was sequenced as a doublestranded DNA by the dideoxy chain-termination method (Sanger et al., 1977) using the modified T7 polymerase, Sequenase (USB). Convenient restriction fragments were either subcloned into pBluescript and sequenced using universal primers or $10 \mathrm{a} 1$ was sequenced directly using synthetic oligonucleotide primers: F1, 5'-GGATCATACCATAGC-3'; F2, 5'CGCTCTTTACAGCGG-3' ${ }^{\prime}$ F3, 5'-GATGAATTAAAAGGC-3'; F4, 5'-CCTGGTCTAAACCCATCC-3'; AP1, 5'-GAAATTGTGTTAAAACCAATCGTTC-3'; AP2, 5'-GCAAAAT-
TCCACGCGTTGTAGAAGTG-3'; AP3, 5'-GACATTTTGCGTATAACCACTAG-3'; P1, 5'-CACACATATGTCTTGC$3^{\prime}$.

Protein techniques. Whole-cell proteins of $C$. jejuni NCTC 11168 and $E$. coli with or without phagemid 10a1 were resolved by SDS-PAGE $[0 \cdot 1 \%(\mathrm{w} / \mathrm{v}) \mathrm{SDS}, 12 \%(\mathrm{w} / \mathrm{v})$ polyacrylamide] and either stained with Coomassie Blue R-250 or transferred to Immobilon membranes (Millipore). Western blotting was carried out using a Bio-Rad mini-transblot system according to the manufacturer's instructions. Bound antibodies were detected using anti-rabbit and anti-human IgG (Fc fragment) conjugated to alkaline phosphatase (Life Technologies) and detected with nitro blue tetrazolium (Sigma) and 5-bromo-4 chloro-3-indolyl phosphate (Sigma) as previously described (Griffiths et al., 1992).

Induction of recombinant protein. An overnight culture of $E$. coli $\mathrm{PLKF}^{\prime}$ containing the excised phagemid was inoculated into $50 \mathrm{ml} \mathrm{LB}$ broth containing $50 \mu \mathrm{g}$ ampicillin $\mathrm{ml}^{-1}$ and incubated for $2 \mathrm{~h}$ with shaking, until an $\mathrm{OD}_{600}$ of 0.5 was reached. After this time $10 \mathrm{mM}$ IPTG was added and incubation continued for a further $2-3 \mathrm{~h}$. The culture was then cooled on ice, centrifuged at $3000 \mathrm{~g}$ and the cells immediately added to SDS-PAGE loading buffer. After boiling for $3 \mathrm{~min}$, samples were resolved by SDS-PAGE.

Cell fractionation studies. In order to determine the location of the recombinant protein in $E$. coli, induced cells were fractionated into outer-membrane and cytosolic fractions and examined by Western blotting. Cells were disrupted by sonication, membranes were separated by centrifugation and the supernatant fluid (cytosolic fraction) was collected. Outer membranes were prepared by the method of Carlone $e t$ al. (1986). Periplasmic shock proteins were prepared as described by Logan \& Trust (1983).

$\mathrm{N}$-terminal amino acid sequencing. Automated gas-phase $\mathrm{N}$ terminal amino acid sequencing was undertaken directly on the two protein products after resolution by SDS-PAGE and transfer to Immobilon membranes (Matsudaira, 1987).

Northern blotting. This was carried out using Amersham Hybond $\mathbf{N}$ nylon membranes according to the protocol provided by the manufacturer. Blots were probed with ${ }^{32} \mathrm{P}-$ labelled 10a1 insert, prepared using the Boehringer Mannheim Random Primed DNA labelling kit according to the manufacturer's instructions.

Transcript mapping. Transcription start points were determined by primer extension. Total RNA for primer extension was extracted from cells of $C$. jejuni NCTC 11168 in the exponential, late-exponential and stationary growth phases, as determined from contemporaneous growth curves of viable counts. Briefly, cells were grown with shaking in Nutrient Broth no. 2 (Oxoid; CM67) at $37^{\circ} \mathrm{C}$ in gas jars and viable counts were made at appropriate intervals. Cells from each time point were examined by light microscopy after heat fixing and staining with crystal violet as previously described (Griffiths, 1993). Approximately $100 \mathrm{mg}$ cells were resuspended in $0.5 \mathrm{ml}$ lysis buffer $(0.6 \mathrm{M} \mathrm{NaCl}, 10 \mathrm{mM}$ EDTA, $100 \mathrm{mM}$ Tris $/ \mathrm{HCl}$ $\mathrm{pH} 8.0$ ), and lysed by addition of $0.25 \mathrm{ml} 10 \%$ (w/v) SDS. An equal volume of TE (10 mM Tris/ $\mathrm{HCl} \mathrm{pH} 8 \cdot 0,1 \mathrm{mM}$ EDTA) saturated phenol was then added and the tubes were shaken for $15 \mathrm{~min}$ at room temperature. Following centrifugation at $10000 \mathrm{~g}$ for $5 \mathrm{~min}$ the aqueous phase was transferred to a clean tube and extracted twice with diethyl ether to remove traces of phenol. An equal volume of $8 \mathrm{M} \mathrm{LiCl}$ was then added and the tubes incubated overnight at $4{ }^{\circ} \mathrm{C}$. The tubes were vortexed briefly and centrifuged at $10000 \mathrm{~g}$ for $10 \mathrm{~min}$. The pellet was 
resuspended in a mixture of $0.3 \mathrm{ml} \mathrm{H}_{2} \mathrm{O}, 0.03 \mathrm{ml} 3 \mathrm{M}$ sodium acetate $\mathrm{pH} 5.2$ and $0.75 \mathrm{ml}$ ethanol. After storage at $-70^{\circ} \mathrm{C}$ for $30 \mathrm{~min}$ the tubes were centrifuged at $10000 \mathrm{~g}$ for $10 \mathrm{~min}$. The pellet was washed with $70 \%(\mathrm{v} / \mathrm{v})$ ethanol then dried and redissolved in $20 \mu \mathrm{l}$ diethyl-pyrocarbonate-treated $\mathrm{H}_{2} \mathrm{O}$. The oligonucleotide primer $\mathrm{F} 4$ was radioactively end-labelled by phosphorylation with $\left[\gamma^{32} \mathrm{P}\right]$ ATP $\left(3000 \mathrm{Ci} \mathrm{mmol}^{-1}, 111 \mathrm{TBq}\right.$ $\mathrm{mmol}^{-1}$; Amersham) using T4 polynucleotide kinase (Gibco$\mathrm{BRL}$ ). The radiolabelled primer was hybridized to approximately $20 \mu \mathrm{g}$ total Campylobacter RNA for $2 \mathrm{~h}$ at $37^{\circ} \mathrm{C}$ in reverse transcriptase buffer (Gibco-BRL). Following hybridization, dNTPs were added ( $1 \mathrm{mM}$ of each) and the DNA/RNA hybrids were then incubated for $2 \mathrm{~h}$ at $37^{\circ} \mathrm{C}$ with 100 units Superscript reverse transcriptase (Gibco-BRL). A $10 \mu$ laliquot was added to $4 \mu \mathrm{l}$ sequencing gel loading buffer and the samples were heated to $98{ }^{\circ} \mathrm{C}$ for $10 \mathrm{~min}$ before loading onto a $8 \%$ polyacrylamide/urea sequencing gel alongside a sequencing reaction of phagemid 10a1 DNA primed with the same primer. Campylobacter RNA samples subjected to RNase treatment did not act as a substrate for the reverse transcriptase.

Isolation of overlapping clones. In order to obtain sequence upstream from the primary clone, DNA/DNA hybridization was used to screen plaques from the lambda ZAP II library. The entire $1.6 \mathrm{~kb}$ fragment from phagemid $10 \mathrm{a} 1$ was labelled with $[\alpha-$ $\left.{ }^{32} \mathrm{P}\right] \mathrm{dATP}$ using a random prime kit (Megaprime, Amersham) according to the manufacturer's instructions. DNA from $2 \times 10^{4}$ plaques was bound to nylon membranes (Hybond- $N$, Amersham) according to the manufacturer's instructions. The probe DNA was hybridized to the plaque DNA at $65^{\circ} \mathrm{C}$ and washed using stringent conditions according to Amersham's protocol. Following autoradiography, positive plaques were picked and phagemids containing recombinant inserts were excised as before, in order that the DNA sequence could be determined. Southern blots of genomic DNA were also performed to demonstrate that the overlapping sequences possessed co-linear restriction sites with the cloned DNAs. These blots demonstrated that no additional unaccountable restriction fragments hybridized to the trigger factor probe. The sequences are therefore likely to be unique within the Campylobacter genome.

\section{RESULTS}

\section{Immunoscreening of Campylobacter gene library}

A recombinant library containing random chromosomal fragments of $C$. jejuni NCTC 11168 in lambda ZAP II was constructed. Approximately 20000 plaques from this expression library were screened with serum raised in rabbits to $\mathrm{AE}$. The anti-AE serum detected four positive plaques from the library. In vivo excision of one of these positive lambda clones (10a) to give phagemid 10a1 allowed over-expression of the recombinant protein in $E$. coli in response to IPTG induction. SDS-PAGE of IPTGinduced $E$. coli demonstrated the expression of the recombinant protein, clearly showing a polypeptide of approximately $56 \mathrm{kDa}$ with a second less intense band of approximately $52 \mathrm{kDa}$ (Fig. 1a). Both the $56 \mathrm{kDa}$ and the $52 \mathrm{kDa}$ bands reacted with anti-AE serum on Western (a)

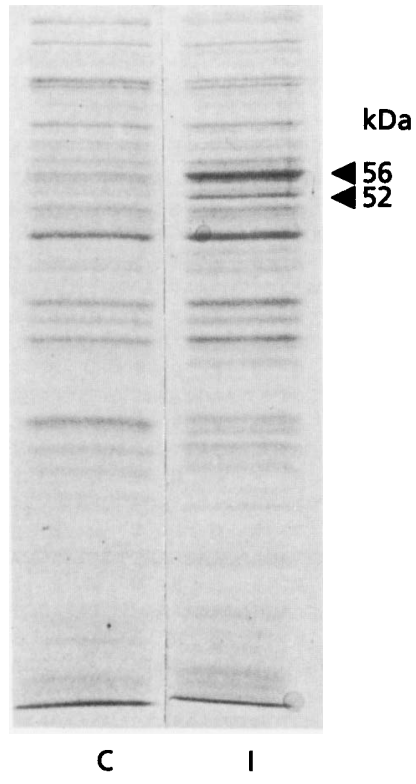

(b)

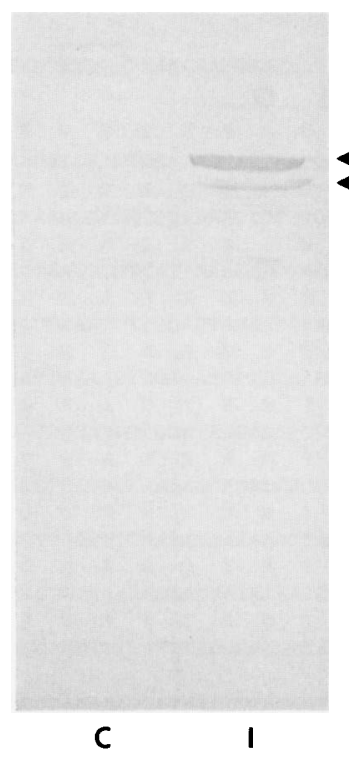

(c)

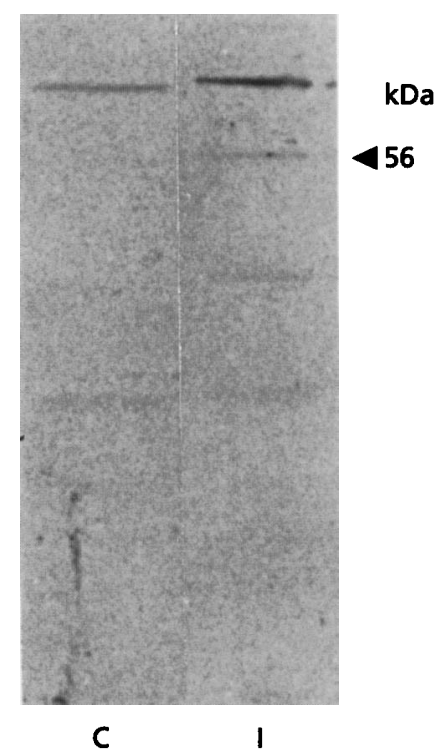

Fig. 1. In vivo excision of lambda clone 10a to give a phagemid 10a1 allowed IPTG-induced expression of the recombinant protein in E. coli PLKF'. Lanes: C, whole cells of control strain without phagemid; I, induced whole cells of strain with phagemid $10 \mathrm{a} 1$. Arrowheads indicate $56 \mathrm{kDa}$ and $52 \mathrm{kDa}$ recombinant proteins attributable to the $10 \mathrm{a} 1$ coding sequences. Other additional protein bands were equally reproducible upon induction of a phagemid-containing control. (a) SDS-PAGE gel (12\%) stained with Coomassie blue; (b) Western blot of whole-cell proteins incubated with rabbit anti-AE serum; (c) Western blot of whole-cell proteins incubated with human serum from a patient infected with C. jejuni. 
(a)

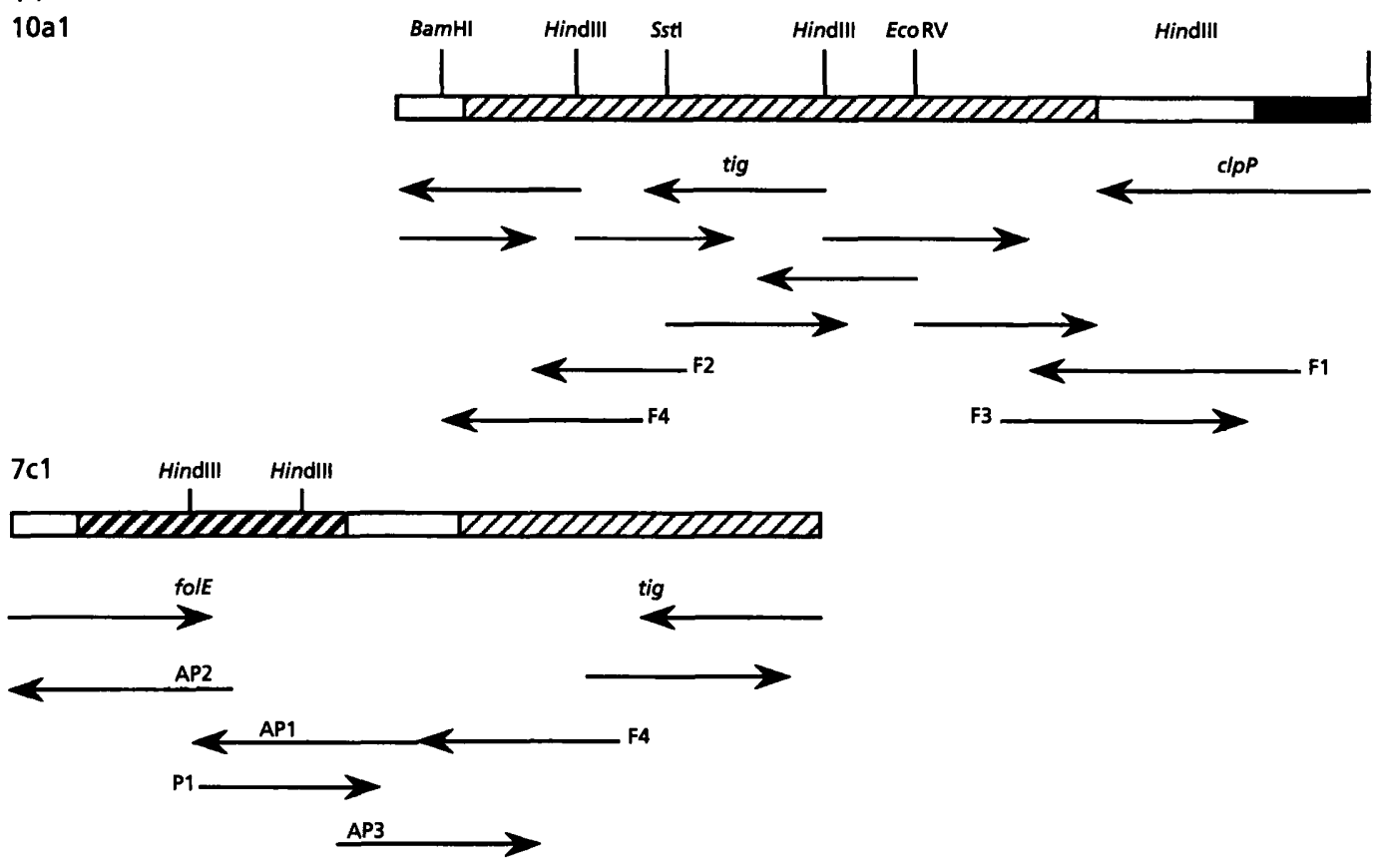

(b)

-662 AAAATATCACTTAAATTTTCTTTCCAAGTTTGGAGCGTAGTTTTTCAAGATTCATTAAAT $\begin{array}{lllllllllllllllllllllllllllllllllllllllll}R & V & O & K & A & S & N & I & L & S & F & F & E & E & R & I & K & B & N & K & I & F & I & G & R & L & A & S & S & T & T & T & T & S & N & A & K & Q & V & G\end{array}$ CTTACCTGTTTAGCAGAGTTPATGAGAGAAAAAAATTCCTCTCTAATTTPTTCATTTTTTAAGAAAATTCCACGTAAAGCTGAAGAAGTTGTAGTGGTGGAATTAGCTTTTTGCACTCCA

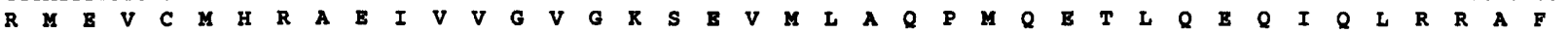
CGCATTTCAACACACATATGTCTTGCTTCTATGACTACACCCACACCTTTTGACTCGACCATTAAAGCTTGTGGCATPTGTTCAGTAAGTTGTTCTTGAATTTGAAGTCTTCTTGCAAAC

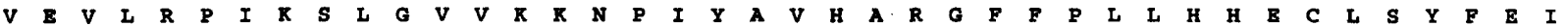
ACTTCTACAAGGCGTGGATTTTGCTTAAACCTACTACTTTTTTATTAGgGATATAGGCTACATGAGCACGCCCAAAAAAAGgCAAAAGATGATGTTCGCAAAGACTGTAAAATTCTATA

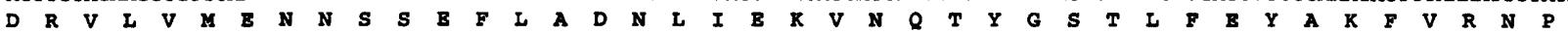
TCACGCACTAAAACCATTTCATTATTAGAACTTTCAAATAAAGCGTCATTTAAGATTTCTTTGACATTTTGCGTATAACCACTAGTAAGAAATTCATAAGCTTTAAAAACACGATTTGGC

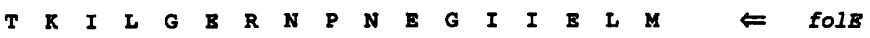

GTTTTAATAAGCCCTTCACGATTTGGATTTTCTCCTATAATTPTCAAGCATGGTTTTAACACAATCTTCAAATTTTTTTTGCACATTTTTCTCCAAAAATATTTTTTTATAILTTAA

$$
\text { P1 }
$$

1 ATGTAATATTGCAATI $\rightarrow$ P3 2

$\begin{array}{llllllllllllllllllllllllllllllllllllllll}K & O & L & D & S & V & N & A & T & A & S & V & K & I & P & S & G & M & I & K & S & E & V & E & N & L & A & K & K & A & S & K & S & V & K & M & D & G & F & R\end{array}$ AAG EAAC) $\begin{array}{lllllllllllllllllllllllllllllllllllllllll}P & G & R & V & P & V & S & A & V & I & K & R & Y & E & R & B & L & S & Q & D & A & E & Q & N & L & F & K & S & A & V & N & S & A & L & Q & E & L & K & K & E\end{array}$ CCAGGAAAAGTTCCTGTAAGTGCCGTACTTAAAAGATATGAAAGAGAGCTCTCTCAAGATGCAGAACAAAATCTTTTTAAATCCGCTGTAAATAGCGCTTTACAAGAACTTAAAAAAGAA $\begin{array}{llllllllllllllllllllllllllllllllllllllll}N & K & E & L & V & G & E & P & Y & F & E & K & F & D & R & R & D & G & E & I & I & A & E & L & I & L & S & F & K & P & E & I & K & L & E & G & Y & E & K & L\end{array}$ AATAAAGAGCTTGTAGGTGAGCCATATTTTGAAAAATTTGATCGTAAAGATGGAGAAATTATTGCTGAATTAATACTTTCTTTTAAACCTGAAATCAAACTTGAGGGTTATGAAAAACTC $\begin{array}{llllllllllllllllllllllllllllllllllllllllll}I & P & E & Y & Q & T & P & K & V & S & K & K & E & I & D & E & K & K & D & E & L & L & K & R & F & A & T & P & E & A & I & K & T & K & R & A & I & K & E & G\end{array}$ ATCCCTGAATATCAAACTCCAAAAGTAAGTAAAAAAGAAATTGATGAGAAAAAAGATGAGCTTTTAAAGCGTTTTGCTACTCCTGAAGCTATAAAAACAAAAAGAGCTTTAAAAGAAGGT

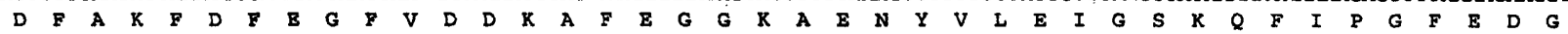
GATTTTGCAAAATTTGATTTTGAAGGTTTTGTAGATGATAAAGCTTTTGAAGGTGGTAAAGCTGAAAATTATGTTTTAGAAATTGGTTCTAAGCAATTTATTCCAGGTTTTGAAGATGGT

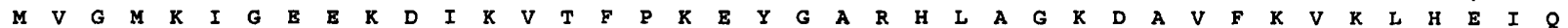
ATGGTGGGAATGAAAATAGGTGAAGAAAAAGATATCAAAGTAACTTTCCCTAAAGAATACGGCGCACGGCATTTAGCGGGTAAAGATGCAGTATTTAAAGTAAAACTACATGAAATTCAA

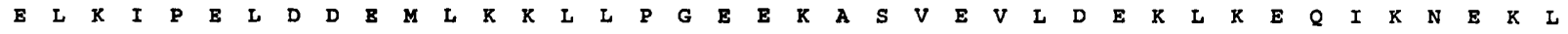
GAGCTTAAAATTCCAGAACTTGATGATGAAATGCTTAAAAAACTTTTACCAGGAGAAGAAAAAGCTAGTGTTGAAGTTTTAGATGAAAAATTAAAAGAGCAAATCAAAAATGAAAAACTT

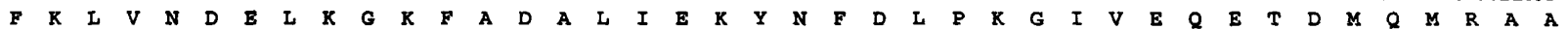
TTCAAACTTGTAAATGATGAATTAAAAGGCAAATTTGCAGATGCTTTGATTGAAAAATATAATTTTGATTTACCTAAAGGCATAGTAGAACAAGAAACTGATATGCAGATGCGTGCGGCT $\begin{array}{lllllllllllllllllllllllllllllllllllllllll}F & N & T & F & C & E & K & E & I & B & E & L & K & A & S & K & E & K & Y & Q & E & K & R & D & S & F & K & E & E & A & Q & K & S & V & K & I & T & F & I & I\end{array}$ TTTAATACTTTTTGCGAAAAAGAAATTGAAGAGCTTAAAGCAAGTAAAGAAAAATATCAAGAAAAACGTGATTCTTTTAAAGAAGAAGCACAAAAAAGTGTAAAACTTACTTTTATCAT?

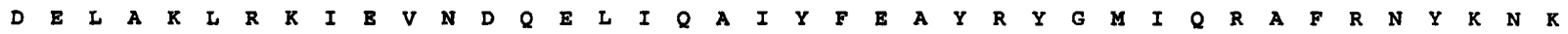
GATGAACTTGCAAAATTGCGTAAGATTGAAGTAAATGATCAAGAATTGATTCAAGCGATTTATTTTGAAGCATATCGCTATGGTATGATCCAAAGAGCATTTAGAAACTATAAAAACAAG B L C L L * ClPP $\Rightarrow \quad M \quad F$

1321 GAGCTTTGCCTGCTGTGAAAATGGCTYTAATTGAAGAAAACTTTTTAATGATATTTTTATACCAAAAACAGAAAAATCAGAAAAAGTGAGCAAAAAAGAGAAAGAAGATAAATAATGTTT

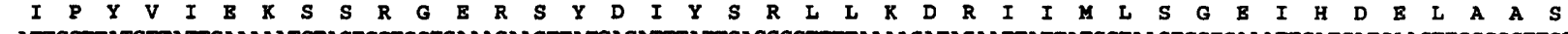

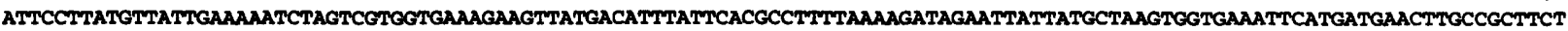

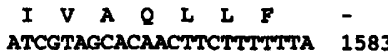

Fig. 2. Complete nucleotide sequence of the insert of clone 10a1 (nucleotides 1 to 1583) together with the upstream region from clone $7 \mathrm{cl}$ (nucleotides -1 to -662 ) showing that the direction of translation of the Campylobacter folE gene is in the opposite direction to that of the Campylobacter tig gene. (a) Restriction map of phagemids 10a1 and 7c1 and region of overlap showing sequencing strategy of the ORFs. (b) Nucleotide sequence and deduced amino acid 
(a)

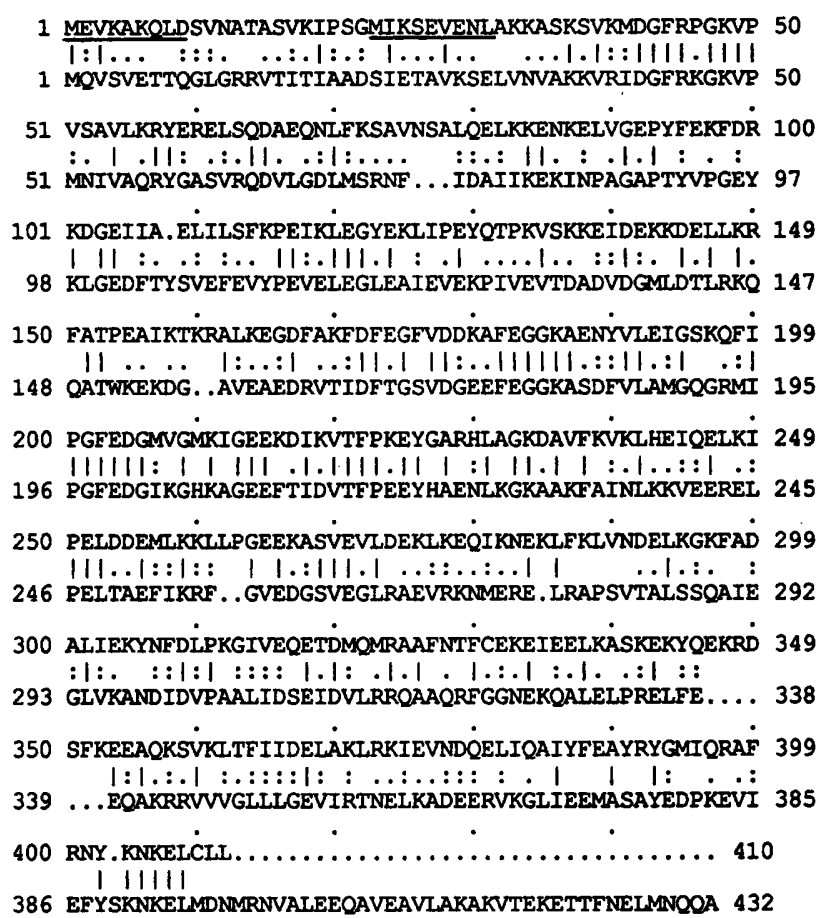

(b)

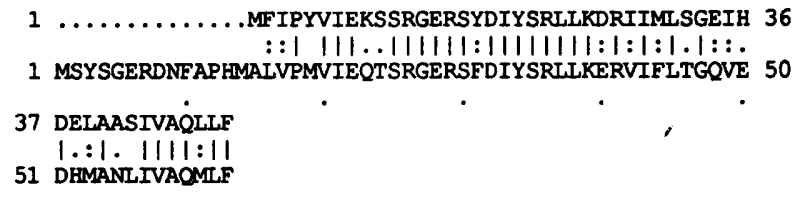

Fig. 3. Amino acid alignments of protein sequences derived from clone 10a1. (a) Amino acid alignment of ORF1 from clone $10 a 1$ (top) with E. coli trigger factor (bottom). (b) Amino acid alignment of ORF2 from clone $10 \mathrm{a} 1$ (top) with $E$. coli ClpP (bottom). The experimentally determined amino-terminal protein sequences (underlined) were in complete agreement with the amino acid sequences arising from the external and internal initiating methionines predicted from nucleotide sequence data. These data were used for comparison to the PIR (release 42.0) and SwissProt (release 30.0) protein databases (programs FASTA and BLAST; Altschul et al., 1990; Pearson \& Lipman, 1988). Conserved amino acids are indicated by vertical lines and conservative replacements are indicated by double dots.

blots (Fig. 1b). Western blotting experiments using serum from a patient infected with $C$. jejuni revealed a reactive band of $56 \mathrm{kDa}$ (Fig. 1c). An antigen of similar molecular mass has also been noted as an antigen common to several Campylobacter strains (Blaser et al., 1984). Sera from two other convalescent patients also recognized the main band as well as cross-reacting with some of the $E$. coli proteins.
By contrast, sera from two further convalescent patients gave no reaction with either polypeptide, which is perhaps not surprising considering the variability of the human response (see Introduction).

\section{Characterization of cloned gene}

Phagemid $10 \mathrm{a} 1$ contained a DNA insert of approximately $1.6 \mathrm{~kb}$, the complete sequence of which revealed an open reading frame (ORF) of 410 codons (nucleotides 1-1583; Fig. 2a, b). The sequences were compared to existing sequence databases (PIR release 42.0 and SwissProt release 30.0) using the programs FASTA and BLASTX (Pearson \& Lipman, 1988; Altschul et al., 1990). The ORF had an amino acid identity of $31 \%$ with $E$. coli trigger factor (Fig. 3a). Trigger factor, encoded by the tig gene, was discovered in $E$. coli by its ability to stabilize proOmpA in a membrane assembly competent form but later was found not to play a direct role in the in vivo synthesis and export of proOmpA (Guthrie \& Wickner, 1990). N-terminal amino acid sequence data of the $56 \mathrm{kDa}$ recombinant protein (underlined in Fig. 3a) confirmed the expression of the ORF. The $\mathrm{N}$-terminal sequence was also determined for the $52 \mathrm{kDa}$ protein observed by SDSPAGE. Because this protein was found to commence with a methionine and to possess an $\mathrm{N}$-terminal sequence corresponding to the initiation of $E$. coli trigger factor it is most likely that it arises from an internal initiation codon producing a similar protein product, less the first 22 amino acids (also underlined in Fig. 3a). However, the possibility that it is formed by proteolytic processing of the $56 \mathrm{kDa}$ protein has not yet been ruled out. A smaller ORF containing a truncated sequence of 49 codons fused to the vector was also identified in the database search. The truncated reading frame had an amino acid sequence identity of $31 \%$ with ClpP of E. coli. ClpP is the proteolytic component of the ATP-dependent Clp protease of E. coli (Maurizi et al., 1990). The gene product of clpP, like that of tig, has been suggested to have a chaperone function and the two genes are similarly sequentially organized in E. coli (Squires \& Squires, 1992). Their comparative conservation may be related to a need to express the chaperones coordinately in response to growth conditions. Interestingly, the pre-sequence observed in E. coli ClpP is missing from the Campylobacter $\mathrm{N}$-terminal sequence.

The polypeptide product of the 410 -codon ORF has a predicted molecular mass of $47226 \mathrm{Da}$, somewhat smaller than that observed from SDS-PAGE gels. Trigger factor from $E$. coli also demonstrated this discrepancy, with a molecular mass of $60 \mathrm{kDa}$ estimated from SDS-PAGE (Crooke \& Wickner, 1990) and an ORF encoding a protein of $47993 \mathrm{Da}$ (Guthrie \& Wickner, 1990), a similar size to the Campylobacter protein. The large proportion of charged residues found in the predicted protein sequences

sequences of the ORFs of the inserts in clones $10 \mathrm{a} 1$ and $7 \mathrm{c} 1$. The ORF for the folE gene homologue extends from nucleotides -70 to -596 . The ORF for the tig gene homologue extends from nucleotides 106 to 1336 . The ORF for the truncated $c / p P$ gene homologue starts at nucleotide 1435. Putative ribosome-binding sites are underlined. Transcription start sites determined by primer extension are marked with solid arrows and their corresponding putative promoter elements are boxed. The two potential initiation codons for the tig ORF are marked 1 and 2 in reverse field. 
(a)
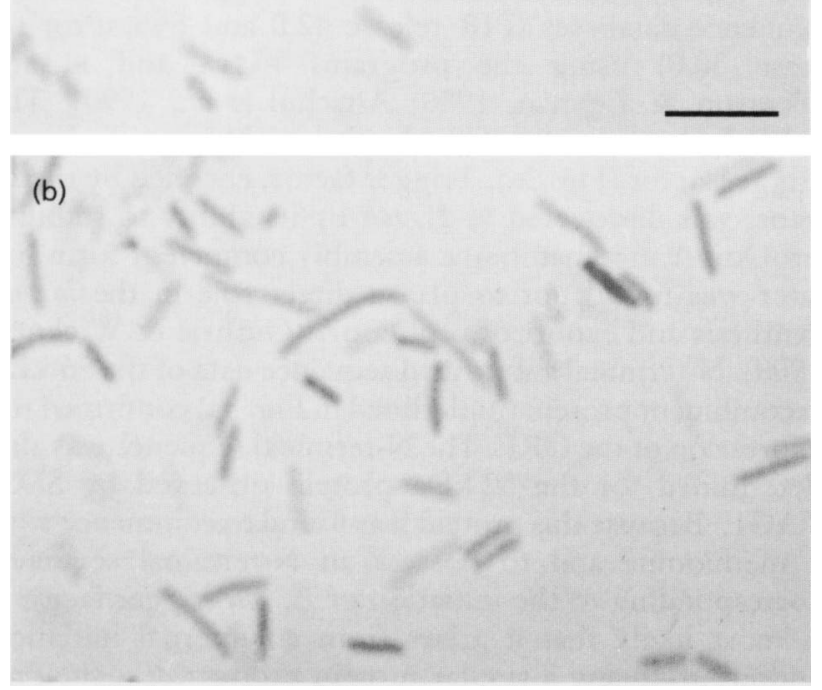

Fig. 4. Morphology of $E$. coli cells expressing Campylobacter trigger factor. (a) $E$. coli host PLKF' stained with carbol fuchsin following induction with IPTG (0.4 mM); (b) PLKF' cells carrying the phagemid 10a1 treated as above. Bar, $10 \mu \mathrm{m}$. Alternative PLKF' cultures bearing the phagemid alone or bearing other recombinant Campylobacter phagemids did not demonstrate the elongated cell phenotype attributable to the Campylobacter trigger factor gene.

may be responsible for the discrepancy. The putative Campylobacter trigger factor was found to be associated mainly with the cytosol of $E$. coli expressing recombinant protein; it was also detected by Western blotting in outer membrane and periplasmic fractions prepared as detailed in Methods (data not shown).

\section{Determination of the sequence upstream from Campylobacter tig}

Two clones were obtained by DNA/DNA hybridization (using 10a1 insert to probe the lambda ZAP II library) that overlapped the $10 \mathrm{a} 1$ clone with additional sequence upstream. One of these, phagemid $7 \mathrm{c} 1$, contained a $1.4 \mathrm{~kb}$ insert which overlapped $10 \mathrm{a} 1$ by approximately $0.7 \mathrm{~kb}$, giving $0.7 \mathrm{~kb}$ of new sequence. The DNA sequence of this clone was determined and analysed as before. A restriction map of $7 \mathrm{c} 1$ is shown in Fig. 2(a); the sequences additional to phagemid 10a1 are shown as bases -1 to -662 in Fig. 2(b). The additional DNA sequence revealed an ORF translated from the opposite direction to tig, encoding a protein of 178 codons. The translated sequence was found to show $53 \%$ identity to human GTP cyclohydrolase I, which catalyses dihydroneopterin triphosphate formation from GTP (Togari et al., 1992). The protein sequence also showed $48.3 \%$ and $39.4 \%$ identity, respectively, to the equivalent ORFs of Bacillus subtilis (mtr $A$ ) and E. coli (folE) (Gollnick et al., 1990; Katzenmier et al., 1991). The arrangement of these genes in Campylobacter is different from that of E. coli, where the gene immediately upstream, and translated in the same direction as tig, is bolA. The bol $A$ gene has been shown to possess a growth-phasedependent promoter that is activated in stationary phase (Aldea et al., 1989).

\section{Cell division defect and growth phase regulation}

Trigger factor may have a role in cell division, possibly acting as a chaperone to other proteins involved in septation (Guthrie \& Wickner, 1990). Incomplete septation was observed by Guthrie \& Wickner (1990) in trigger-factor-depleted cells and in cells over-expressing the native tig gene. These effects were suppressed by cooverexpression of the crucial cell division gene $f t s Z$. Campylobacters have been observed to adopt filamentous forms on transition from exponential to stationary phase (Griffiths, 1993), implying that certain cell division genes are affected by growth phase. In addition, Tai et al. (1992) reported that levels of the protein encoded by secI (tig) increased on entry to stationary phase in E. coli.

We therefore examined transcription of the Campylobacter tig gene with respect to growth phase and cell division. It was also noted that overproduction of Campylobacter trigger factor in E. coli resulted in the elongation of the host cells (Fig. 4). RNAs were isolated from campylobacters harvested after culture in liquid medium during the exponential, late-exponential, stationary and death phases. As described by Griffiths (1993) the campylobacters became more filamentous in form upon entering late-exponential phase, eventually adopting coccal morphology at death phase. We could not isolate RNA from such coccal cultures. The total transcriptional levels detected on Northern transfers of the growth-phasespecific RNA preparations did not indicate a clear relationship between growth phase and changes in transcript levels detected. The Northern blot also failed to provide clear evidence as to the programmed use of the second AUG which gives rise to the shorter translation product observed. However, from the Northern blots the transcript size could be estimated to be $2 \cdot 2 \mathrm{~kb}$ (Fig. 5), somewhat larger than that required for the tig gene alone. Significantly, the upstream ORF (GTP cyclohydrolase I) is encoded in the opposite strand, implying that two divergent transcripts arise from the intergenic region. It is therefore likely, based on the size of the tig transcript, that it is co-transcribed with the downstream $c l p P$ gene.

\section{Transcript mapping}

The Campylobacter tig gene encodes two polypeptides, of 410 and 388 amino acids, each initiated by an AUG codon (nucleotides 106 and 172) and terminated by the chaintermination codon UGA (nucleotide 1336). Putative ribosome-binding sites are indicated in Fig. 2(b) directly 


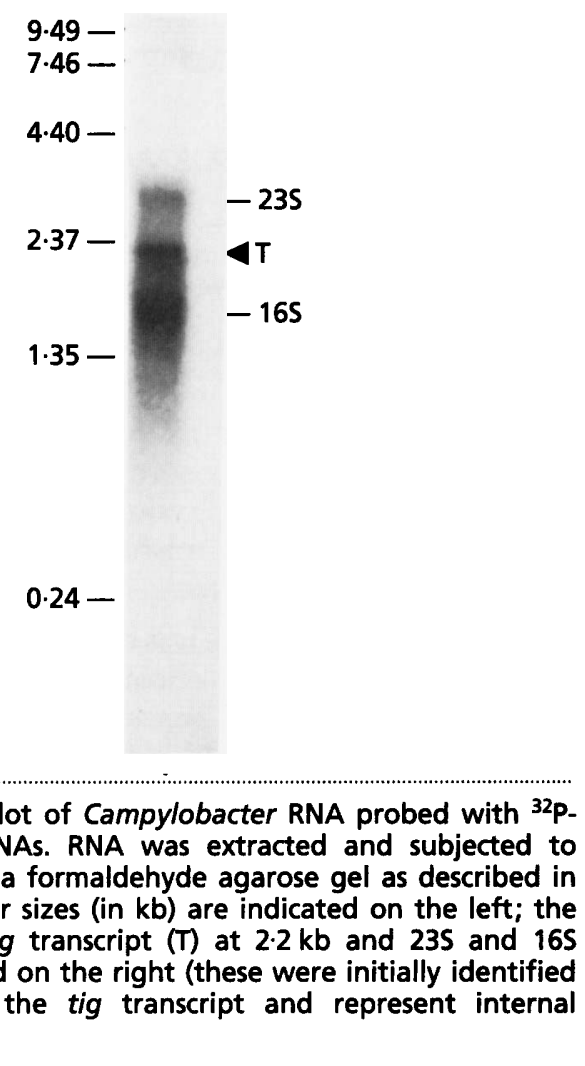

Fig. 5. Northern blot of Campylobacter RNA probed with ${ }^{32} \mathrm{p}$ labelled cloned DNAs. RNA was extracted and subjected to electrophoresis on a formaldehyde agarose gel as described in Methods. Molecular sizes (in kb) are indicated on the left; the positions of the tig transcript $(T)$ at $2.2 \mathrm{~kb}$ and 235 and $16 \mathrm{~S}$ rRNAs are indicated on the right (these were initially identified independently of the tig transcript and represent internal controls).

upstream from the initiation codons. As the Northern blot provided little information regarding regulation of the Campylobacter tig gene or the use of the alternative initiation codons, transcript mapping was therefore undertaken. The tig gene transcription start sites were determined by primer extension from RNAs isolated during the mid-exponential and early stationary phases of growth (Fig. 6). The evidence suggests there are three main transcription start sites utilized during exponential growth, the first (P1) initiating at nucleotides 29/31, the second (P2) at nucleotide 78 and the third (P3) at nucleotide 163. The P3 start site is inside the reading frame specified by the first initiation codon. This shorter transcript will therefore translate from the second inframe AUG using the preceding putative ribosomebinding site. It is notable that this promoter continues to operate into stationary phase whereas the P1 and P2 promoters, specifying the larger translation product, begin to decline. Examination of the putative -10 and -35 promoter elements revealed no significant homology with those common for other bacterial genera. The -13 guanine-centred consensus sequence (TTGCT) attributed to $\sigma^{54}$-dependent function is present upstream of the P2 transcript. The $\mathrm{P} 1$ and $\mathrm{P} 3$ promoters also feature similar sequences further upstream, at -20 and -15 , respectively. However, the consensus guanine residues at -24 and -25 for the $\sigma^{54}$ promoter are either absent or shifted by 2 bp in the case of the P2 promoter. The $\sigma^{54}$ RNA polymerase holoenzyme transcribes a diverse set of genes from various bacterial species, including those whose products are involved in nitrogen assimilation, those which encode pilins necessary for human cell

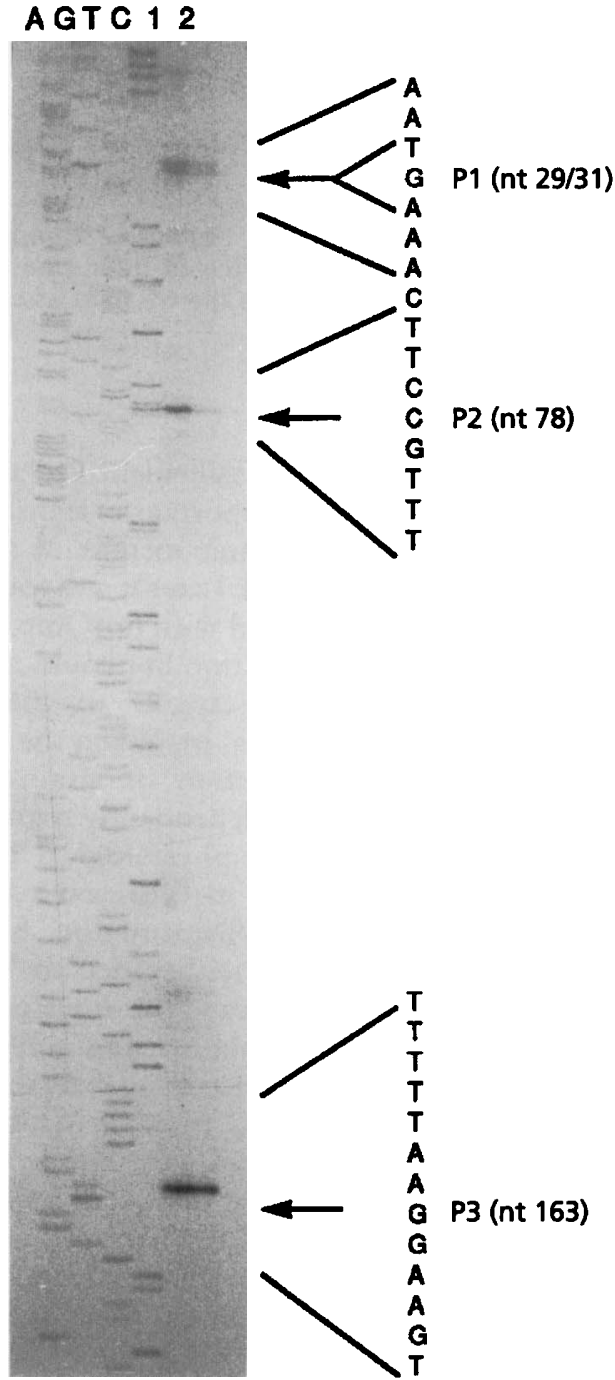

Fig. 6. Mapping the transcripts of the Campylobacter tig gene at two different phases of growth. Primer extension products were generated after reverse transcription of total RNAs isolated from exponential (1) and early stationary phase (2) cells. The primer extension products were co-electrophoresed on an $8 \%$ sequencing gel against dideoxy sequencing reactions primed with the same primer (F4).

attachment in pathogenic species (Kustu et al., 1989) and, perhaps significantly, the weaker of the two flagellin gene promoters $(f a B)$ from campylobacters (Guerry et al., 1991). The upstream sequences of Campylobacter tig and the published sequence of $f a B$ are compared in Fig. 7, showing the similarity of the two sequences. The promoter structure of the Campylobacter tig gene suggests that it contains sequences that allow for closely regulated, probably growth-phase-dependent, transcription. It is notable that the amino acid homology observed with $E$. coli begins after the $\mathrm{N}$-terminal extension directed from the first AUG. High-titre antiserum to purified E. coli trigger factor did not react with the Campylobacter homologue by Western blotting, despite the amino acid sequence similarity. 
TTITAATTAAAACTIGGAACACTTCTTECTTIAATCTTTCGATGCAATATTTTGAAAGGATTAAAATG

AAT TTATGCAAGTAATAAGAAAATITECTATCATTGAGGCAAATTTTATTTTATAAGGAAAAACTATG

tig

Fig. 7. Alignment of upstream regions of Campylobacter tig with the published sequence of flaB (Guerry et al., 1991). Transcription start sites are indicated by arrows; -10 and -35 regions are boxed; putative ribosome-binding sites are underlined; also underlined are the GG pairs associated with $\sigma^{54}$ function.

\section{DISCUSSION}

Trigger factor in E. coli was originally identified as one of a number of proteins that were important in translocation of proOmpA across the cytoplasmic membrane (Crooke \& Wickner, 1987; Lill et al., 1988). Later it was found that although trigger factor co-purified with proOmpA it was not in fact necessary for translocation but could maintain proOmpA in a conformation capable of membrane translocation (Crooke et al., 1988a, b). When the tig gene was isolated, allowing construction of strains where expression of trigger factor is independently regulated, it became apparent that the main physiological effect of altering levels of trigger factor in cells was to inhibit normal cell division, leading to filamentation. Since the filamentation occurring in cells either depleted for or overproducing trigger factor can be suppressed by simultaneous over-expression of the essential cell division gene $f t s Z$, it has been suggested that trigger factor has an important role in cell division, possibly acting as a chaperone (Guthrie \& Wickner, 1990). Similarly overexpression of the Campylobacter tig gene also leads to the filamentation of $E$. coli cells. It has also been proposed that the product of the tig gene (described as SecI), has a regulatory function in protein translocation across bacterial cytoplasmic membranes (Tai et al., 1992). The precise physiological function of this essential gene product remains obscure.

Campylobacter trigger factor is clearly highly immunogenic in rabbits immunized with $\mathrm{AE}$ and reacts with human convalescent sera. The less abundant shorter version of the Campylobacter tig gene product was not detected on Western blots with human convalescent sera. This may reflect the relative abundance of the two proteins in the Campylobacter cell. However, it is notable that the 22amino-acid sequence that distinguishes these products has little similarity with the $E$. coli protein: proper alignment of these sequences is only possible after the second Campylobacter initiating methionine (Fig. 3a).

As in E. coli, the ORF following tig in Campylobacter encodes ClpP, the proteolytic component of the ATPdependent Clp protease which is thought to be involved in the turnover of aberrantly folded proteins (Squires \& Squires, 1992). Considering the size of the Campylobacter mRNA $(2 \cdot 2 \mathrm{~kb})$ and the determined transcription start sites, the $c l p P$ gene is likely to be co-transcribed with tig. Whether $c l p P$ is also independently transcribed from within the short non-coding region between the reading frames has not yet been determined. However, considering the relative abundance of the trigger factor protein in the cell and its possible growth-phase-dependent regulation, the coordinate of $\mathrm{ClpP}$ protease is likely to have a critical physiological significance in the control and turnover of misfolded proteins under suboptimal growth conditions.

The Campylobacter tig gene was expressed in E. coli without some of the problems encountered by others when expressing Campylobacter genes in foreign hosts. C. jejuni trigger factor has been identified as a major antigenic component in acid-glycine extract, which is often used as a standard antigenic preparation in serological studies of the species. The gene shows several interesting features, including multiple transcription start sites, co-transcription, an unusual $\sigma^{54}$-like promoter, and growth-related regulation.

\section{ACKNOWLEDGEMENTS}

This work was supported by the University of Reading Research Endowment Fund and by the Wellcome Trust (Grant no. 038228). We would like to thank Professor William Wickner for the gift of the antiserum to $E$. coli trigger factor.

\section{REFERENCES}

Aldea, M., Garrido, T., Hernandez-Chico, C., Vicente, M. \& Kushner, S. N. (1989). Induction of a growth-phase-dependent promoter triggers transcription of bolA, an Escherichia coli morphogene. EMBO J 8, 3923-3931.

Alm, R. A., Guerry, P. \& Trust, T. J. (1993). Significance of duplicated flagellin genes in Campylobacter.J Mol Biol 230, 359-363.

Altschul, S. F., Gish, W., Miller, W., Myers, E. W. \& Lipman, D. J. (1990). A basic local alignment search tool. J Mol Biol 215, 403-410.

Black, M. J., Perlman, D., Clements, M. L., Levine, M. M. \& Blaser, M. J. (1992). Human volunteer studies with Campylobacter jejuni. In Campylobacter jejuni: Current Status and Future Trends, pp. 207-215. Edited by I. Nachamkin, M. J. Blaser \& L. S. Tomkins. Washington, DC: American Society for Microbiology.

Blaser, M. J. \& Duncan, D. J. (1984). Human serum antibody response to Campylobacter jejuni infection as measured in an enzymelinked-immunosorbent assay. Infect Immun 44, 292-298.

Blaser, M. J., Hopkins, J. A. \& Vasil, M. L. (1984). Campylobacter jejuni outer membrane proteins are antigenic for humans. Infect Immun 43, 986-993.

Bolton, F. J. \& Coates, D. (1983). A study of the oxygen and carbon dioxide requirements of thermophilic campylobacters. J Clin Patbol 36, 829-834.

Carlone, G. M., Thomas, M. L., Rumschlay, H. A. \& Sottnek, F. O. (1986). Rapid microprocedure for isolating detergent-insoluble outer membrane proteins from Haemopbilus species. J Clin Microbiol 24, 330-332. 
Crooke, E. \& Wickner, W. (1987). Trigger factor: a soluble protein that folds pro-OmpA into a membrane-assembly-competent form. Proc Natl Acad Sci US A 84, 5216-5220.

Crooke, E., Guthrie, B., Lecker, S., Lill, R. \& Wickner, W. (1988a). ProOmpA is stabilised for membrane translocation by either purified E. coli trigger factor or canine signal recognition particle. Cell 54, 1003-1011.

Crooke, E., Brundage, L., Rice, M. \& Wickner, W. (1988b). ProOmpA spontaneously folds in a membrane assembly competent state which trigger factor stabilizes. EMBO J 7, 1831-1835.

Gollnick, P., Ishino, S., Kuroda, M. I., Henner, D. J. \& Yanofsky, C. (1990). The $m$ tr locus is a two-gene operon required for transcription attenuation in the trp operon of Bacillus subtilis. Proc Natl Acad Sci US A 87, 8726-8730.

Griffiths, P. L. (1993). Morphological changes of Campylobacter jejuni growing in liquid culture. Lett Appl Microbiol 17, 152-155.

Griffiths, P. L. \& Park, R. W. A. (1990). Campylobacters associated with human diarrhoeal disease. J Appl Bacteriol 69, 281-301.

Griffiths, P. L., Moreno, G. S. \& Park, R. W. A. (1992). Differentiation between thermophilic Campylobacter species by species-specific antibodies. J Appl Bacteriol 72, 467-474.

Guerry, P., Logan, S. M., Thornton, S. \& Trust, T. J. (1990). Genomic organisation and expression of Campylobacter flagellin genes. J Bacteriol 172, 1853-1860.

Guerry, P., Alm, R. A., Power, M. E., Logan, S. M. \& Trust, T. J. (1991). Role of two flagellin genes in Campylobacter motility. $J$ Bacteriol 17, 4757-4764.

Guerry, P., Alm, R. A., Power, M. E. \& Trust, T. J. (1992). Molecular and structural analysis of Campylobacter flagellin. In Campylobacter jejuni: Current Status and Future Trends, pp. 276-281. Edited by I. Nachamkin, M. J. Blaser \& L. S. Tompkins. Washington, DC: American Society for Microbiology.

Guthrie, B. \& Wickner, W. (1990). Trigger factor depletion or overproduction causes defective cell division but does not block protein export. J Bacteriol 172, 5555-5562.

Herbrink, P., van den Munckhof, H. A. M., Bumkens, M., Lindeman, J. \& van Dijk, W. C. (1988). Human serum antibody response in Campylobacter jejuni enteritis as measured by enzymelinked immunosorbent assay. Eur J Clin Microbiol Infect Dis 7, 388-393.

Katzenmeier, G., Schmid, C., Kellermann, J., Lottspeich, F. \& Bacher, A. (1991). Sequence of GTP cyclohydrolase I from Escherichia coli. Biol Chem Hoppe-Seyler 372, 991-997.

Kustu, S., Santero, E., Keener, J., Popham, D. \& Weiss, D. (1989). Expression of $\alpha^{54}(n \operatorname{tr} A)$-dependent genes is probably united by a common mechanism. Microbiol Rev 53, 367-376.

Lill, R., Crooke, E., Guthrie, B. \& Wickner, W. (1988). The 'trigger factor cycle' includes ribosomes, presecretory proteins and the plasma membrane. Cell 54, 1013-1018.

Logan, S. M. \& Trust, T. J. (1983). Molecular identification of surface protein antigens of Campylobacter jejuni. Infect Immun 4, 675-682.

Maniatis, T., Fritsch, E. F. \& Sambrook, J. (1982). Molecular Cloning: a Laboratory Manual. Cold Spring Harbor, NY : Cold Spring Harbor Laboratory.
Matsudaira, P. (1987). Sequence from picomole quantities of proteins electroblotted onto polyvinylidene difluoride membranes. J Biol Chem 262, 10035-10038.

Maurizi, M. R., Clark, W. P., Katayama, Y., Rudikoff, S., Pumphrey, J., Bowers, B. \& Gottesman, S. (1990). Sequence and structure of ClpP, the proteolytic component of the ATP-dependent Clp protease of Escherichia coli. J Biol Chem 265, 12536-12545.

McCoy, E. C., Burda, D. D., Corbeil, L. B. \& Winter, A. J. (1975). Superficial antigens of Campylobacter ( $V$ ibrio) fetus: characterization of an antiphagocytic component. Infect Immun 11, 517-525.

Mills, S. D. \& Bradbury, W. C. (1984). Human antibody response to outer membrane proteins of Campylobacter jejuni during infection. Infect Immun 43, 739-743.

Nachamkin, I. \& Hart, A. M. (1985). Western blot analysis of the human antibody response to Campylobacter jejuni cellular antigens during gastrointestinal infection. J Clin Microbiol 21, 33-38.

Panigrahi, P., Losonsky, G., DeTolla, L. J. \& Morris, J. G. (1992). Human immune response to Campylobacter jejuni proteins expressed in vivo. Infect Immun 60, 4938-4944.

Pearson, W. R. \& Lipman, D. J. (1988). Improved tools for biological sequence comparison. Proc Natl Acad Sci USA 85, 2444-2448.

Pei, Z. \& Blaser, M. J. (1993). PEB1, the major cell-binding factor of Campylobacter jejuni, is a homolog of the binding component in Gram-negative nutrient transport systems. I Biol Chem 268, 18717-18725.

Sanger, F., Nicklen, S. \& Coulson, A. R. (1977). DNA sequencing with chain-terminating inhibitors. Proc Natl Acad Sci USA 74, 5463-5467.

Short, J. M., Fernandez, J. M., Sorge, J. A. \& Huse, W. D. (1988). Lambda Zap: a bacteriophage lambda expression vector with in vivo excision properties. Nucleic Acids Res 16, 7583-7600.

Squires, C. \& Squires, C. L. (1992). The Clp proteins: proteolysis regulators or molecular chaperones? J Bacteriol 174, 1081-1085.

Svedhem, A., Gunnarsson, H. \& Kaijser, B. (1983). Diffusion-in-gel enzyme-linked immunosorbent assay for routine detection of IgG and IgM antibodies to Campylobacter jejuni. J Infect Dis 148, 82-92.

Tai, P. C., Lian, J., Yu, N.-J., Fandl, J., Xu, H. \& Vidugiriene, J. (1992). On protein translocation across cytoplasmic membranes. Antonie Leeuwenboek 61, 105-109.

Taylor, D. E. (1992). Genetics of Campylobacter and Helicobacter infection. Annu Rev Microbiol 46, 35-64.

Togari, A., Ichinose, H., Matsumoto, S., Fujita, K. \& Nagatsu, T. (1992). Multiple mRNA forms of human GTP cyclohydrolase I. Biochem Biophys Res Commun 187, 359-365.

Walker, R. I., Caldwell, M. B., Lee, E. C., Guerry, P., Trust, T. J. \& Ruiz-Palicios, G. M. (1986). Pathophysiology of Campylobacter enteritis. Microbiol Rev 50, 81-94.

Wassenaar, T. M., Bleumink-Puym, J. \& Van der Zeijst, B. A. M. (1991). Inactivation of Campylobacter jejuni flagellin genes by homologous recombination demonstrates that $f a A$ but not $f a B$ is required for invasion. EMBO J 10, 2055-2061.

Received 12 September 1994; revised 23 February 1995; accepted 8 March 1995. 